\title{
Modeling and Aiding Intuition: \\ Introduction to the commentary section
}

\author{
Julian N. Marewski*, Ulrich Hoffrage*, Ronald P. Fisher** \\ *University of Lausanne, Switzerland; **Florida International University, USA
}

\begin{abstract}
Address Correspondence to:
Julian N. Marewski or Ulrich Hoffrage, University of Lausanne

Faculty of Business and Economics, Department of Organizational Behavior

Quartier UNIL-Dorigny, Bâtiment Internef, CH-1015 Lausanne, Switzerland

Email: julian.marewski@ unil.ch or ulrich.hoffrage@unil.ch
\end{abstract}

Ronald P. Fisher, Florida International University

Department of Psychology

3000 N.E. 151st Street, North Miami, FL 33181-3600, U.S.A.

Email: fisherr@fiu.edu

Please cite the commentary section as:

Hoffrage, U., Marewski, J. N., \& Fisher, R. P. (2016). Modeling and aiding intuitions:

Commentaries. Journal of Applied Research in Memory \& Cognition, $x x, x x-x x$. 


\begin{abstract}
This section of JARMAC includes a series of commentaries on articles published in the September, 2015, special issue of JARMAC: „Modeling and aiding intuition in organizational decision making" (Marewski \& Hoffrage, 2015). The commentaries focus on research programs such as naturalistic decision making, heuristics-and-biases, ACT-R, and CLARION. They feature topics ranging from evolution to decision styles. In this introduction, we provide a brief overview of those contributions, alongside with concluding words on this project of pulling together multiple and very different strands on intuition.
\end{abstract}

Keywords: Intuition, deliberation, analysis, reason, heuristics, cognitive architectures, naturalistic decision making, evolution. 
Not too long ago, one of us stood, in the evening twilight, on top of a hill, letting his gaze wander across a valley. On the other side of the valley, the eye met distant trees, and then, all of a sudden, partly veiled by branches and wagering fog: a fallen column, remnants of an amphitheatre, and a small, round temple. These ruins were not built by ancient Rome's architects, as one might suspect, but crafted during the Enlightenment. The ruins' hidden, foggy romance contrasts with the aesthetics of a beautiful palace, built on the very same hill from which this scene unfolds. This palace is intact, characterized by ordered shapes, colonnades, and statues. It sits on top of that hill like a jewellery-braced crown, with majestic stairs reaching down and widening into an open park landscape - that of Sanssouci, Potsdam, Germany.

The dialectics of these two poles - the ruins in the distance, dreamt-up re-creations of a once powerful empire, and the seemingly more modern palace with its intact golden lines, clear structure, and order on the hill - is akin to the contrast that forms the central theme of this special issue and its commentaries: The savage, almost ancestral mysticism of intuition, gut feelings, and subjective hunches on the one hand, and the majestic, enlightened garments of reason, rationality, and careful analysis on the other hand.

\section{What is intuition?}

The ideal of using rational, reasoned analysis to understand the world dates back, at least, to the Enlightenment. Nowadays, it continues to be strong in academia, business, medicine, and other areas of professional activity - together with the belief that subjective intuitions are something inferior, preferably avoided in serious scientific or other professional activities. Many authors juxtapose intuition to reason and embed both in long lists of associates, such as feelings and heuristic shortcuts on the one hand, and analysis and slow thinking on the other hand - just think of the title of Kahneman's (2011) bestseller "Thinking, fast and slow". The associates, in 
turn, are given different connotations, with those linked to intuition ranging from animalistic to fast but error-prone, and those linked to "reason" from optimal to rational. Yet, despite having some idea of what intuition is to them personally, many scientists seem to be at pains to specify precisely what it is, so that one single, commonly agreed-upon definition does not exist. Contrary to reason - which can be cast in terms of models of logic, careful information integration, or optimization - intuition remains, scientifically, an elusive notion.

Indeed, one striking observation we noted when putting together the special issue (Marewski \& Hoffrage, 2015) and the present commentary section (Hoffrage, Marewski, \& Fisher, 2016) is that there is little consensus in the literature as to what intuition is and how it ought to be studied. Different authors link intuition to diverse definitions and notions, including the unconscious, the opposite of reason, or heuristics. Moreover, studies of intuition use diverse methodologies, ranging from plain story-telling to experimental work and computer simulations. In this introduction, we will illustrate those different views on - and their corresponding methodological approaches to - intuition by providing a brief overview of the commentaries.

\section{Views on intuition}

Intuition seen in different dimensions and domains. What is intuition? Various authors of the special issue focus on single - and different - aspects of intuition, such as unconscious decision-making (Chassot, Klöckner, \& Wüstenhagen, 2015), holistic decision-making (Brown \& Daus, 2015), or effortless decision-making (Baron, Scott, Fincher, \& Metz, 2015). Others, in contrast, including ourselves (Hoffrage \& Marewski, 2015), see multiple dimensions of intuition. Amit, Rusou, and Arieli (2016, THIS ISSUE) contrast those various uni-dimensional and multidimensional conceptualizations of intuition and review research that tested whether there is an empirical basis to separate various dimensions of intuition. 
Independent of whether intuition is conceptualized as a uni-dimensional or multidimensional concept, several interesting questions, both theoretical and applied, mark the field: When should one follow one's intuition, and when should one adopt an analytical decision style? And what do people actually do? Do the answers to these prescriptive and descriptive questions depend on the domain? After all, when looking at ourselves, as researchers, we find that in most of our scientific work, we claim to stay on one pole: Experiments, computer code, numbers, logic, and scientific reasoning. Yet, deeply inside we all know that for many - if not most - of our scientific insights our intuitions played an eminent role as well. And when it comes to romantic love, most would hasten to stress that they did not espouse their romantic partners solely based on analysis and without listening to their intuitions and feelings (Gigerenzer, 2014).

Two of the articles in the special issue address the question whether and when people favor intuition over analysis. Specifically, Brown and Daus (2015) probed police officers' behavior (more spontaneously and affect-laden vs. more deliberate and rational) in two different situations, and Pachur and Spaar (2015) asked students for their preferences to use intuition versus analysis in six different domains. Olds and Link (2016-THIS ISSUE) build on Pachur and Spaar's findings, namely that people's preferences for one or the other style are domainspecific, and they discuss two possible sets of explanations for such domain-specific preferences: One can be found in objective characteristics of the domain itself (e.g., predictability of events; see also Shanteau, 2015), and the other one in individual differences (e.g., with respect to expertise).

Szaszi (2016-THIS ISSUE) also expands upon Pachur and Spaar (2015), but raises a conceptual issue: Is people's tendency to adopt an intuitive decision style the same as their 
preference for that style? Szaszi warns that these two concepts should not be used interchangeably.

Intuition reflected in clashes and conflicts. Kurt Lewin (1952) once remarked, "There is nothing more practical than a good theory" (p. 169). Yet theory and practice do not always find each other, and sometimes, the two even conflict. Gore and Conway (2016-THIS ISSUE), discusses the contrast of intuition and analysis in the fuzzy and uncertain world of organizations, that is, in practice. Similar to Brown (2015), they call for a hybrid approach that combines intuition and analysis, and discuss (a) ways to build bridges between academia and practice and (b) how research in general and intuition research in particular can have greater impact on policy and practitioners.

Frey, Neys, and Bago (2016-THIS ISSUE) also focus on conflict, albeit not on the conflict between theory and practice, but on conflicts between intuitive and analytic forms of thinking, most notably between scientific theories that conceive of such forms of thinking in different ways. For example, within the fast-and-frugal heuristics framework (e.g., Gigerenzer, Todd, \& the ABC Research Group, 1999; Hafenbrädl, Wäger, Marewski, \& Gigerenzer, in press) heuristic decision making processes - linked to intuition (e.g., Gigerenzer, 2007, 2014) - are thought of underlying fast, but possibly also very smart and adaptive judgments and decisions. Similarly, research on naturalistic decision making (e.g., Klein, Orasanu, Calderwood, \& Zsambok, 1993) stresses the clever nature of intuitive decision making processes. On the other hand, the heuristics-and-biases research program (e.g., Kahneman, Slovic, \& Tversky, 1982) and associated work on System-1/System-2 dichotomies highlighted the superiority of analytic, deliberate over intuitive, heuristic processes. In their commentary, Frey et al. focus on what 
happens when individuals detect that intuitive processes produce outcomes that violate normative standards (see also Dhami, Belton, \& Goodman-Delahunty, 2015).

Intuition cast into the language of mathematics and computer code. In the cognitive and decision sciences, a fundamental question is how people arrive at their judgments and how they make decisions in situations of risk or uncertainty. The language to describe those situations is that of mathematics: Variables or clues in the environment (e.g., a person's reputation) correlate with unknown criteria (e.g., whether this person will cooperate in a given situation), and, by assessing those environmental cues, individuals can try to infer those criteria. This conceptualization of decision making environments in terms of formal language is also key to other approaches to judgment and decision making that have been featured in this special issue. Cases in point are White, Pothos, and Busemeyer's (2015) quantum probability theory approach, judgment analysis in the Neo-Brunswikian tradition (Hammond, 2015), or, to a more limited extent, research within the heuristics-and-biases program, namely when equations are used to define what might be adequate solutions to a given decision problem (see Dickert, Västfjäll, Kleber, \& Slovic, 2015). Yet, formal language does not only lend itself to model how judgments and decisions ought to be made and in what environmental context they are made, but also to model how people actually make them. In the special issue, examples of attempts to computationally model intuition are the cognitive model CLARION (Connectionist Learning with Adaptive Rule Induction ON-line; Sun, 2015) or the ACT-R cognitive architecture (Adaptive Control of Thought - Rational, Thomson, Lebiere, Anderson, \& Staszewski, 2015; Juvina, Lebiere, \& Gonzalez, 2015). In their commentary, Larue and Juvina (2016-THIS ISSUE) discuss further how ACT-R could be used to implement the tri-partitive framework of Stanovich (2009). According to this framework, the human mind can be decomposed functionally into an 
autonomous mind, an algorithmic mind, and a reflective mind. Larue and Juvina propose that the algorithmic mind, for instance, might be modeled in terms of ACT-R's memory mechanisms with its underlying mathematical equations.

In another commentary, Bear and Rand (2016-THIS ISSUE), in turn, invoke computer simulations as means towards building theories on the likely origins of intuition. Specifically, they demonstrate that formal models inspired by evolutionary game theory can help explain why intuitions might have evolved even though agents who process information more thoroughly outperfom "intuitive" agents.

\section{Conclusion}

How shall we model and aid intuition? One answer that is commonly found in the judgment and decision making literature is: Understand the nature of experience! A second alternative is Klein's (2003) recognition-primed decision model (see also Klein, 2015; or Shanteau, 2015). Still others, at least when it comes to aiding, are "simulated experience" and story-telling (Hogarth \& Soyer, 2015). Even more answers - some complimentary, other not have been formulated in the 23 manuscripts published in the special issue and its commentary section (see entries with $*$ and $* *$, respectively, in the reference list below).

Intuition, so we realized in the course of almost four years of editorial work, continues to be a beautiful, elusive subject of scientific inquiry that seems to shy away from the light of analysis and that behaves like an inkblot test or a chameleon - different people construe intuition in different ways (see also Raue et al., 2015). Indeed, when pulling the different contributions to this special issue together in our introductory article (Hoffrage \& Marewski, 2015), we pointed out that intuition as a topic of scientific inquiry is very different from other topics. It not only calls for analytical and empirical methods of scientific inquiry, but also for insight and Gestalt. 
Much can be learned about intuition through scientific definitions, equations, computer simulations, or experiments. At the same time, much would also be missed if one relied exclusively on such approaches - which was, in many ways, a surprising insight for us as experimentally-working psychologists and/or computational modellers. Intuition comes as an inner feeling, as a messenger from our unconscious, as something undefinable, but yet illuminating and powerful. Gestalt-inducing media, such as pictures, poetry, or other artworks, can transport that insight and get across some flavour of intuition's mystery. This flavour is, interestingly, not so distinct from the sentiments one can have when looking, during sunset, at the scenery described above, the ruin hill of Sanssouci: A breeze of romantic longing for something that is hidden and occult, yet, at the same time intimately related to us and our own origin.

Acknowledgements. We thank four anonymous reviewers and various authors of the articles published in Marewski and Hoffrage (2015) for constructive feedback on the commentaries submitted to this special section. Furthermore, we express our gratitude to the Swiss National Science Foundation for supporting the research in which this special issue is embedded (SNF 100014-146702 and 100014-140503/1) as well as to the editorial staff at the publisher, especially Thiyagarajan Sivakumar. 


\section{References}

Articles that appeared in the original special issue are marked with *; commentaries are marked with **.

**Amit, A., Rusou, Z., \& Arieli, S. (2016). Uni-dimensional or multi-dimensional? Empirical evidence for distinguishing between different aspects of intuition. Journal of Applied Research in Memory and Cognition, $x x, x x-x x$.

Anderson, J. R., \& Lebiere, C. (1998). The atomic components of thought. Mahwah, NJ: Erlbaum.

*Baron, J., Scott, S., Fincher, K., \& Metz, S. E. (2015). Why does the Cognitive Reflection Test (sometimes) predict utilitarian moral judgment (and other things)? Journal of Applied Research in Memory and Cognition, 4(3), 265-284.

**Bear, A., \& Rand, D. G. (2016). Modeling intuition's origins. Journal of Applied Research in Memory and Cognition, $x x, x x-x x$.

*Brown, R.V. (2015). Decision science as a by-product of decision-aiding: A practitioner's perspective. Journal of Applied Research in Memory and Cognition, 4(3), 212-220.

*Brown, S. G., \& Daus, C. S. (2015). The influence of police officers' decision-making style and anger control on responses to work scenarios. Journal of Applied Research in Memory and Cognition, 4(3), 294-302.

*Chassot, S., Klöckner, C. A., \& Wüstenhagen, R. (2015). Can implicit cognition predict the behavior of professional energy investors? An explorative application of the Implicit Association Test (IAT). Journal of Applied Research in Memory and Cognition, 4(3), 285293.

*Dhami, M., Belton, I., \& Goodman-Delahunty, J. (2015). Quasirational models of sentencing. Journal of Applied Research in Memory and Cognition, 4(3), 239-247.

*Dickert, S., Västfjäll, D., Kleber, P., \& Slovic, P. (2015). Scope insensitivity: The limits of intuitive valuation of human lives in public policy. Journal of Applied Research in Memory and Cognition, 4(3), 248-255.

**Frey, D., de Neys, W., \& Bago, B. (2016). The jury of intuition: Conflict detection and intuitive processing. Journal of Applied Research in Memory and Cognition, $x x, x x-x x$.

Gigerenzer, G. (2007). Gut feelings: The intelligence of the unconscious. New York: Viking Press.

Gigerenzer, G. (2014). Risk savvy: How to make good decisions. New York: Viking.

Gigerenzer, G., Hertwig, R., Hoffrage, U., \& Sedlmeier, P. (2008). Cognitive illusions reconsidered. In C. R. Plott \& V. L. Smith (Eds.), Handbook of Experimental Economics Results (Vol. 1, pp. 1018-1034). Amsterdam: North Holland/Elsevier Press.

Gigerenzer, G., Todd, P. M., \& the ABC Research Group (1999). Simple heuristics that make us smart. New York: Oxford University Press.

**Gore, J., \& Conway, G. E. (2016). Modeling and aiding intuition in organizational decision making: A call for bridging academia and practice. Journal of Applied Research in Memory and Cognition, $x x, x x-x x$. 
Hafenbrädl, S., Wäger, D., Marewski, J. N., \& Gigerenzer, G. (in press). Applied decision making with fast-and-frugal heuristics. Journal of Applied Research in Memory and Cognition.

Hammond, K. R. (1996). Human judgment and social policy: Irreducible uncertainty, inevitable error, unavoidable injustice. Oxford, England: Oxford University Press.

*Hammond, K. R. (2015). Causality vs generality: Judgment and decision making struggles to become a scientific discipline. Journal of Applied Research in Memory and Cognition, 4(3), 176-179.

*Hoffrage, U., \& Marewski, J. N. (2015). Unveiling the Lady in Black: Modeling and aiding intuition. Journal of Applied Research in Memory and Cognition, 4(3), 145-163.

Hoffrage, U., Marewski, J. N., \& Fisher, R. P. (2016). Modeling and aiding intuitions: Commentaries. Journal of Applied Research in Memory and Cognition, $x x, x x-x x$.

*Hogarth, R. M., \& Soyer, E. (2015). Providing information for decision making: Contrasting description and simulation. Journal of Applied Research in Memory and Cognition, 4(3), 221-228.

*Juvina, I., Lebiere, C., \& Gonzalez, C. (2015). Modeling trust dynamics in strategic interaction. Journal of Applied Research in Memory and Cognition, 4, 197-211.

Kahneman, D. (2011). Thinking, fast and slow. Macmillan.

Kahneman, D., Slovic, P., \& Tversky, A. (1982). Judgment under uncertainty: Heuristics and biases. New York: Cambridge University Press.

Klein, G. A. (2003). The power of intuition: How to use your gut feelings to make better decisions at work. New York: Currency.

*Klein, G. A. (2015). A naturalistic decision making perspective on studying intuitive decision making. Journal of Applied Research in Memory and Cognition, 4(3), 164-168.

Klein, G. A., Orasanu, J. M., Calderwood, R., Zsambok, R. (Eds.). Decision making in action: Models and methods. Norwood, NJ: Ablex Publishing.

**Larue, O., \& Juvina, I. (2016). A call for unification of dual- and single-process accounts in cognitive models of intuition. Journal of Applied Research in Memory and Cognition, xx, $x x-x x$.

Lewin, K. (1952). Field theory in social science: Selected theoretical papers by Kurt Lewin. London: Tavistock.

Marewski, J. N., \& Hoffrage, U. (2015). Modeling and aiding intuition in organizational decision making. [Special Issue.] Journal of Applied Research in Memory and Cognition, 4, 145311.

**Olds, J. M., \& Link, D. (2016). Unpacking decision domains -- Commentary on "Domainspecific preferences for intuition and deliberation in decision making". Journal of Applied Research in Memory and Cognition, $x x, x x-x x$.

*Pachur, T., \& Spaar, M. (2015). Domain-specific preferences for intuition and deliberation in decision making. Journal of Applied Research in Memory and Cognition, 4(3), 303-311.

*Raue, M., Streicher, B., Lermer, E., \& Frey, D. (2015). How far does it feel? Construal level and decisions under risk. Journal of Applied Research in Memory and Cognition, 4(3), 256-264.

*Shanteau, J. (2015). Why task domains (still) matter for understanding expertise. Journal of Applied Research in Memory and Cognition, 4(3), 169-175. 
Stanovich, K. E. (2009). Distinguishing the reflective, algorithmic, and autonomous minds: Is it time for a tri-process theory? In J. Evans \& K. Frankish (Eds.), In two minds: Dual processes and beyond (pp. 55-88). Oxford: Oxford University Press.

*Sun, R. (2015). Interpreting psychological notions: A dual-process computational theory. . Journal of Applied Research in Memory and Cognition, 4(3), 191-196.

**Szaszi, B. (2016). The role of expertise and preference behind individuals' tendency to use intuitive decision style. Journal of Applied Research in Memory and Cognition, $x x, x x-x x$.

*Thomson, R., Lebiere, C., Anderson, J. R., Staszewski, J. (2015). A general instance-based learning framework for studying intuitive decision-making in a cognitive architecture. Journal of Applied Research in Memory and Cognition, 4(3), 180-190.

*White, L. C., Pothos, E. M., \& Busemeyer, J. R. (2016). Insights from quantum cognitive models for organizational decision making. Journal of Applied Research in Memory and Cognition, 4(3), 229-238. 